\title{
SOCIO-ECONOMIC FACTORS INFLUENCING THE ADOPTION OF HYBRID MAIZE IN GIWA LOCAL GOVERNMENT AREA OF KADUNA STATE, NIGERIA
}

\author{
C.O. Ebojei ${ }^{1}$., T.B.Ayinde ${ }^{2}$ and G.O.Akogwu ${ }^{2}$
}

\begin{abstract}
Maize (Zea mays L.) is one of the most important cereal crops in Nigerian agriculture. The crop occupies a crucial place than other cereal crops since it is used as food, feed, fodder and other industrial raw material. The aim of this study is to identify the socioeconomic factors that influence farmers' decision to adopt hybrid maize in Giwa Local Government Area of Kaduna state, Nigeria using the farm household survey data collected from 160 maize farmers in October-December 2009 for the cropping year 2009-10. This paper presents the results of an empirical application of maximum likelihood estimate of Logit Model to determine the factors influencing farmers' adoption of hybrid maize. The results indicates that the mean predicted probability of technology adoption was Age $\left(X_{1}\right)(P<0.013)$, income $\left(X_{5}\right)(p<0.034)$, education $\left(X_{6}\right)$ $(p<0.001)$ and extension visits $\left(X_{7}\right)(P<0.017)$. On the contrary, farming experience, family size, farm size had no significant influence on participation in hybrid maize. This study suggests the need to bring more area under hybrid maize cultivation. Furthermore, there is a need for special training, seminars, field demonstrations and technical support for the maize farmers. As most of the households had no formal education, the extension program should be intended to the less educated farmers. In addition, the credit facility particularly the procedure for loan should be made simple to improve the adoption rate of hybrid maize in the study area.
\end{abstract}

Key words: adoption, hybrid, maize, socio-economic factors

\section{INTRODUCTION}

In Nigeria, agriculture is one of the intended leading sectors of the economy, in which cereal crops contribute a large share of the output of the agricultural sector; hopefully it should contribute about $30 \%$ of the Gross Domestic Product (GDP) engaging more than $60 \%$ of the labour force. Maize is a popular cereal crop, also known as corn and botanically identified as Zea mays. Maize belongs to the grass family. It is a cereal grain that was domesticated in Mesoamerica and later spread to the rest of the world after European contacts. The Portuguese introduced maize to West Africa in the $16^{\text {th }}$ century (Onwueme, 1979). Maize is

\footnotetext{
${ }^{1}$ Agricultural Policy, Extension and Socio-economic Research Programme, Agricultural Research Council of Nigeria, Abuja.

${ }^{2}$ Department of Agricultural Economics and Rural Sociology, Ahmadu Bello University, Zaria, Nigeria 
The Journal of Agricultural Science, 2012 vol. 7, no 1

a popular cereal crop cultivated for food, feed and fodder. It grows within temperature range of $10-40^{\circ} \mathrm{C}$, the optimum temperature being around $30^{\circ}$ C. Although it requires a great deal of sunshine, low level of humidity, otherwise it is prone to diseases and inadequate pollination, since its root system is shallow as such resistant to drought which is critical during the developmental period of the tassels (Susan and Anne, 1988).

Given these unique nature of maize, researchers through plant breeding have tried to improve the quality and characteristics of maize to suit the various consumers. As maize is becoming the miracle seed for Nigeria's agriculture and economic development (Adeola and Akinwumi, 1993). In Nigeria, many researchers have found improved maize production (hybrid) to be a major factor in an effort to become self-sufficient in maize production. Rapid improvement in production and productivity is important to ascertain the central role of agriculture in Nigerian's economy. It is widely recognised that the sustainable flow and use of improved agricultural technology is the solution to increased growth and agricultural productivity (Ouma et al., 2002). Therefore, a better option is to improve and sustain the production system by providing strong support for greater contribution to national growth.

However, despite the predictable high yield derivable from hybrid maize, the national average grain yields of maize have fallen short consistently of the potential yields (Alamu, 2001). Furthermore in 2005, the Federal
Ministry of Agriculture in its annual report stated that land area under maize cultivation peaked at 5.4 million ha in 1994, it has decreased lately to 4.5 million ha in 2004. Likely factors responsible for the decrease in the production of maize are because of little or no improved seed grown by farmers and lack of response to fertilizer by some local varieties. Other possible factors are increased levels of biotic and abiotic constraints and inflation (Ajala, 2005). Global warming and its associated factors have also changed the pattern of rainfall resulting in unpredictable rainfall which eventually gave rise to drought. Although, extensive reviews of studies on socio-economic as well as demographic factors influencing adoption of hybrid maize has been conducted, so far to assess the factors influencing the farmer's decision on adoption of hybrid maize technology in Giwa Local Government Area. Therefore, the objective of this study is to assess the factors influencing the adoption of hybrid maize technology in the study area. More specifically, it examines current level of adoption of hybrid maize technologies and identifies the major socio-economic factors that influence the adoption of hybrid maize, with a view to providing relevant information to guide farmers, researchers, extension workers and policy makers on this very important maize variety.

\section{MATERIALS AND METHODS Study Area}

This study was conducted in Giwa Local Government Area of Kaduna 
State, which lies between Latitudes $10^{0}$ and $11^{0} 31^{1} \mathrm{~N}$ and Longitudes $7^{0} 30^{\prime}$ and $9{ }^{0} \mathrm{E}$ of the Prime Meridian. Kaduna state is located in the Savannah ecological region of Nigeria, with a cultivatable area of about $34,000 \mathrm{sq} \mathrm{km}$, the actual area cultivated is about $32,230 \mathrm{sq} \mathrm{km}$ from an estimated land area of about $43,000 \mathrm{sq} \mathrm{km}$. The typical weather is mostly categorized by constant dry and wet seasons. The rains begin in April/May and stops in October while the dry season sets in late October and ends in March of the subsequent year. The rainfall duration varies from 150 days (in the Northern parts) to 190 days (in the Southern parts) of the state. The average annual rainfall ranges between $1107 \mathrm{~mm}$ - $1286 \mathrm{~mm}$. Relative humidity varies between $20 \%$ and $40 \%$ in January, and $60 \%$ and $80 \%$ in July. The mean annual high temperature also varies between $34^{\circ} \mathrm{C}$ and $28^{\circ} \mathrm{C}$. Crop cultivation is practiced in the upland and lowland (fadama areas), the farming system in the upland area is essentially rain-fed while in low land areas, both wet and dry season farming occurs. Upland farming is for the most part cereals (like millet, rice, maize and sorghum); legumes (including cowpea; groundnut and soya bean). The lowland farming involves mainly vegetables; tomatoes, pepper and onions. However, there are 23 Local Government Areas (LGAs) in Kaduna State, from which Giwa Local Government Area was purposively selected because of proximity of some institutions and organizations concerned with the adoption of hybrid maize, the intense activities of seed companies in the area and farmer's participation in on-farm trials. Giwa Local Government is located between Latitude $11^{\circ}$ and $12^{\circ} \mathrm{N}$ and Longitude $7^{\circ}$ and $8^{\circ} \mathrm{E}$ of the Prime Meridian (Oguntolu, 2005). Small-scale farmers carry out agricultural production predominantly. The cropping systems in the area are also dominated by mixed cropping, although sole cropping is practiced. In addition, significant parts of the populations are involved in livestock keeping which depends on grazing (Oguntolu, 2005). The nomadic Fulanis predominantly do the grazing and livestock rearing.

\section{Sampling technique and data collection}

Primary data were used for this study. The primary data were collected based on 2009 cropping season using detailed structured questionnaires, with the assistance of an enumerator. The interview methods of data collection were used. The data collected include:

1) demographic information such as age, educational level, occupation, gender, farm size, farming experience; The values were binary in nature 1 indicating farmers who adopted hybrid maize production technology while 0 indicating farmers that did not adopt hybrid maize production technology.

2) production information on hybrid maize, this includes inputs used, like fertilizer, land, seed planted, quality and quantity of input, labour and output/yield; 

The Journal of Agricultural Science, 2012 vol. 7, no 1

3) Finally marketing information like prices of inputs and output, quantity sold, and mode of sales.

The study adopted a cross-sectional sample survey design. The population for the study is dichotomous in nature as such it comprised of hybrid maize and non hybrid maize producers in Giwa Local Government Area of Kaduna State. The list of both hybrid maize and open pollinated maize growers were obtained from the Agricultural Development Programme. This formed the sampling frame for selection of the sample. A multi-stage sampling procedure was applied to select 160 farmers involved in hybrid and open-pollinated maize production. In the first stage, ten wards were purposively selected based on the intensity of maize production. The selection was done to reflect the most typical situation for maize-based farming systems. Secondly, a household was also purposively selected from each of the ward using the above criterion. Finally, 20 households were selected at random from the list of households in the ward to make up a sample size of 160. The surveyed ward were Shika, Giwa, Likoro ,Galadima, Yakawada ,Hayin Madara, Kidandan, Iyatawa ,Maje, and Makarfi.

\section{Model Specification}

A Linear Probability Model (LPM). In a regression model, in which the dependent variable is binary/ dichotomous in nature taking the value 1 and 0 , the use of this model becomes a major problem. The predicted value may fall outside the required range of 0 to1 probability value. Thus, many
Dichotomous (binary) logistic regressions were used to achieve this objective which is to evaluate the factors influencing the adoption of hybrid maize production. Particularly the value 1 was indicated as farmers adopting hybrid maize production technology, while 0 indicates farmers not adopting hybrid maize production technology. Binary logistic regression is a type of regression model where the dependent variable is converted into dichotomous/binary variables coded 0 and 1. The model uses Maximum Likelihood Estimation (MLE) procedure. The advantage of this model is that the probabilities are bound between 0 and 1 . Logit model converts estimated cumulative distribution, therefore eliminating the interval 0 and 1. Unlike the Ordinary Least Square (OLS), although it can be used to estimate binary or dichotomous natured models, certain assumptions of a classical regression model will be violated. Such as non-normality of the disturbance, heteroscedastic variance of the disturbance and a questionable value of $\mathrm{R}^{2}$ as the measure of goodness of fit (Gujarati, 2004).

This eventually expresses itself as follows;

$\mathrm{Y}_{1}=\beta_{0}+\beta_{1} \mathrm{X}_{2}+\mathrm{U}---\cdot--\cdot--\cdot----$

models used in adoption studies fails to meet the statistical assumptions necessary to validate the conclusion based on the hypothesis tested (Feeder et al., 1985). However, in order to overcome the problem associated with LMP, Logit or Probit models have been recommended (Gujarati, 2004). 
The Logistic cumulative probability function can be expressed as.

$\mathrm{P}_{I}=\mathrm{E}\left[\mathrm{Y}=1^{1} / \mathrm{X}_{I}\right]=1 / 1+\ell^{-\left(\beta_{0}+\beta_{1} \mathrm{X}_{1}\right)}$

For ease of expression, one can rewrite the equation as;

$\mathrm{P}_{i}=\quad \frac{1}{1+\ell^{-Z}}=, \frac{\ell^{Z}}{1+\ell^{Z}}$

Where Pi is the probability that the person adopted hybrid maize production technology.

$\mathrm{Zi}=\beta_{0}+\beta_{1} \mathrm{X}_{i}+-\cdot-\cdot------+\beta_{n} \mathrm{X}_{n}$

$\ell$ represents the base of the natural logarithms.

$\mathrm{Z}$ ranges from $-\infty$ to $+\infty$

Although $\mathrm{Z}$ is a linear combination of variables that have both upper and lower bound, none will be used as the variable $Z$. This is because the value of $\mathrm{Z}$ will depend on the value of the unknown parameters $\beta_{i}$ s. To obtain the value of $\mathrm{Z}$, the likelihood of observing, the sample will be formed by introducing a dichotomous response variable Y, such that;

$\mathrm{Y}_{i}=1$ if household adopt hybrid maize invariably; 0 if household do not.

$P$ ranges from 0 and 1

$\mathrm{Pi}$ is nonlinearly related to $\mathrm{Zi}$ (i.e. $\mathrm{Xi}$ ).

Since $\mathrm{Pi}$, which is the probability of adopting hybrid maize is given as equation 3 ,

Then (1- Pi), the probability of not adopting hybrid maize can be expressed as,

$1-\mathrm{P}_{i}=\frac{1}{1+\ell^{Z_{I}}}$

Therefore, we can write

$\frac{P_{i}}{1-P_{i}}=\frac{1+\ell^{Z}}{1+\ell^{-}}=\ell^{Z}$ 
Taking the natural log of equation (5) will give

$\mathrm{Li}=\ln \left[\frac{P_{i}}{1-P_{i}}\right]=\mathrm{Z}_{i}=\beta_{0}+\beta_{1} \mathrm{X}_{1}+\ldots \ldots+\beta_{n} \mathrm{X}$

Where

$\mathrm{L}=\log$ of the odds ratio, not only in $\mathrm{X}$, but also in linear parameters. It is called the logit or logit probability model. This implies that the logistic model explained in the equation is based on the logits of $\mathrm{Z}_{i}$,

$\mathrm{Z}_{i}=$ Stimulus index

The logit model was selected for this study because the dependent variable is dichotomous in nature and the computation will be easier. As mentioned earlier, the adoption or nonadoption of hybrid maize was addressed as a decision involving binary/ dichotomous response variable. These socio-economic factors influencing farmer's adoption or non-adoption of hybrid maize includes the following ; Age of the household head; Number of years of experience in maize farming; Family size; Farm size; Years of formal education; farm income; and finally access to credit/loans. In this study, the focus was farmer's decision to adopt hybrid maize by seeking to quantify the probabilities of socio-economic factors influencing the decision to adopt hybrid maize production by the list obtained from the agricultural development programme of farmers adopting and not adopting hybrid maize production.

The effect of a set of explanatory variables on adoption of hybrid maize is specified using the following expression

Adoption $=\mathrm{f}\left(\mathrm{X}_{1} \mathrm{X}_{2} \mathrm{X}_{3} \mathrm{X}_{4} \ldots \mathrm{X}_{n}\right)$

$Y=\beta_{0}+\beta_{1} X_{1}+\beta_{2} X_{2}+\beta_{3} X_{3}+\ldots \ldots \ldots \ldots \beta_{11} X_{11}+\mu \ldots \ldots(7)$

Where

$\mathrm{Y}=$ a dichotomous response variable such that; $\mathrm{Y}=1$ If farmers adopt hybrid maize and 0 if farmers do not.

$X_{1}=$ Age of the household head (year)

$\mathrm{X}_{2}=$ Number of years of experience in farming 
$\mathrm{X}_{3}=$ Family size

$\mathrm{X}_{4}=$ farm size

$\mathrm{X}_{5}=$ Years of formal education

$\mathrm{X}_{6}=$ visits by extension agents

$\mathrm{X}_{7}=$ Labour

$\mathrm{X}_{8}=$ Income

$\mathrm{X}_{9}=$ Access to credit

$\mu=$ disturbance term or error term which is normally indicated as zero mean and variance

$\mathrm{B}_{1}, \quad \beta_{2} \ldots \beta_{9}$ are the coefficients of the independent variables.

The coefficient of the regression model will be estimated using the maximum likelihood estimating the socio-economic factors influencing the adoption of hybrid maize using an econometric software; LIMDEP.

For easy conversion:

$\$ 1 \mathrm{US}=\$ 150$

$\#$ is the symbol for Nigerian currency - the Naira

Table 01: Mean Socio-economic statistics of maize farmers in Giwa Local Government Area

\begin{tabular}{lll}
\hline Characteristics & Hybrid Maize Farmers & $\begin{array}{l}\text { Open-Pollinated } \\
\text { Maize Farmers }\end{array}$ \\
\hline Age (years) & 40 & 49 \\
Experience in maize production (years) & 11 & 15 \\
Household size & 12 & 14 \\
Farm size (ha) & 05 & 01 \\
Number of extension contact & 03 & 01 \\
Net farm income (N) & 168904.3 & 12378.6 \\
Education: & & \\
No formal education $(\%)$ & 10 & 30 \\
Quranic education $(\%)$ & 10 & 20 \\
Primary education $(\%)$ & 30 & 30 \\
Secondary education $(\%)$ & 45 & 20 \\
Tertiary education $(\%)$ & 05 & 00 \\
\hline
\end{tabular}


The Journal of Agricultural Science, 2012 vol. 7, no 1

\section{Factors influencing adoption of hybrid Maize Production technologies}

The results of the Logit regression model estimating factors influencing participation in hybrid maize production technology are presented in table 02 . The fit of the data was statistically significant at $(\mathrm{P}<0.001)$. The accuracy of the prediction was $97 \%$, while the Nagelkerke $\mathrm{R}^{2}=0.71$. These results show that the specified explanatory variables were able to explain participation in hybrid maize and openpollinated maize production in the study area. The means predicted probability of participation in technology adoption with hybrid maize farmers was found to be (0.87) and (0.23) for open-pollinated maize farmers.

With the exception of age and farm size, all other variables in the model have positive influences on participation in hybrid maize as anticipated. The decisions by households to participate in hybrid maize and open-pollinated maize production were significantly influence by the following household socio-economic variables; Age $\left(\mathrm{X}_{1}\right)$ $(\mathrm{P}<0.013)$, income $\left(\mathrm{X}_{5}\right) \quad(\mathrm{p}<0.034)$, education $\left(\mathrm{X}_{6}\right)(\mathrm{p}<0.001)$ and extension contact $\left(\mathrm{X}_{7}\right)(\mathrm{P}<0.017)$. On the contrary, farming experience, household size and farm size had no significant influence on participation in hybrid maize. Feeder et al (1985) assert that, the positive and significant coefficient of farm size indicates its positive influence on participation in technology adoption.
They said it may be because the farm size is a surrogate for a large number of factors such as size of wealth, access to credit, capacity to bear risk, access to information and other factors. The study reveals that the greater the experience in maize production, the lesser the probability of partaking in hybrid maize production. This is deviating from previous probabilities. The practical effect may possibly be ascribed to the statement that experience farmers may presume to be on familiar terms with open-pollinated maize preventative measure and as a result do not see the need to adopt hybrid maize production technologies. Abebaw and Abelay (2001) reported similar findings. They asserted that coefficient of years of experience was negative and significantly influenced by farmers decision to adopt improved technology in Tanzania. There is a high inclination for farmers who are educated to partake in hybrid maize production technologies compared to those that were illiterates. The odds ration (Exp (B) for this variable was 4.546 which implied that farmers who were educated are 04 times more liable to take part actively in hybrid maize technologies than those who were illiterates. This outcome was likely because those who can read and write are at a lead in perception and deduction of recommended packages. Therefore, the likelihood of participation in hybrid maize production increases with increase in years of schooling, as risk aversion decreases. 
Ebojei C.O., Ayinde T.B. and Akogwu G.O.

Table 02: Socio-Economic factors influencing participation in hybrid and openpollinated maize production:

\begin{tabular}{lllll}
\hline Variable & Notation & Coefficient & $\begin{array}{l}\text { Standard } \\
\text { error }\end{array}$ & Exp (B) \\
\hline Constant & $\mathrm{B}_{\mathrm{o}}$ & 1.679 & 2.397 & 5.362 \\
Age & $\mathrm{X}_{1}$ & -118 & $0.048^{*}$ & 0.889 \\
Farming experience & $\mathrm{X}_{2}$ & .070 & 0.070 & 1.073 \\
Household size & $\mathrm{X}_{3}$ & .053 & 0.061 & 1.055 \\
Farm size & $\mathrm{X}_{4}$ & -0.144 & 0.287 & 0.889 \\
Income & $\mathrm{X}_{5}$ & 0.000 & $0.000^{*}$ & 1.000 \\
Educational status & $\mathrm{X}_{6}$ & 1.514 & $0.463^{*}$ & 4.546 \\
Extension contact & $\mathrm{X}_{7}$ & 0.255 & $0.106^{* *}$ & 1.290 \\
Labour & $\mathrm{X}_{8}$ & 0.000 & $0.000^{*}$ & 1.000 \\
\hline $\mathrm{X}_{2}(\mathrm{df})$ & & & $42.090(\mathrm{P}<0.001) ;$ & $\mathrm{Acc}$ \\
\hline
\end{tabular}

$\mathrm{X}_{2}(\mathrm{df}=8)=62.221(\mathrm{P}<0.001) ;\left(-2 \_\log\right.$ likelihood $=42.090(\mathrm{P}<0.001) ;$ Accuracy of prediction $(\%)=90.9 ;$ Nagelkerke R2 $=0.71$

$*=1 \% * *=5 \%$

The result also suggested that participation in hybrid maize could be motivated by frequent contacts with extension agents. Extension agents popularizes innovation by making farms exchange idea, experiences, and makes it cheaper to source information, knowledge and skills in order to enable farmers to improve their livelihood. Farmers who have frequent contacts with extension agents had a higher probability of participation in the innovation. This was presumed; as farmers were privileged with materials and managerial support, followed by cheap and timely availability of knowledge and skills, which apparently helped them, apply new technology.
This finding is in conformity with Conroy (2005). He found out that frequent contact with The nature and command of age on farmer's contribution to new technology is indecisive. Younger farmers are likely to take up new technology than older farmers being that they are of higher schooling and have more contact to innovations. On the other hand, it may be that older farmers may have extra resource that makes it more likely for them to try new technologies. The studies also suggest that open-pollinated maize production was not labour intensive unlike hybrid maize. Thus the farmers' decision to participate in hybrid maize technology and not open- 
The Journal of Agricultural Science, 2012 vol. 7, no 1

pollinated maize production was not swayed by the family size. This result contradicted the findings of Karki (2004) who observed that farmers participation in maize production was positively related to family size in mid hill region of Nepal.

\section{CONCLUSIONS}

This paper presents the results of an empirical application of maximum likelihood estimate of Logit model to determine the factors influencing farmer's adoption of a technology for hybrid maize production. The findings of this study suggests that five socioeconomic variables; age, income, educational status, labour and extension visits influenced farmer's participation in hybrid maize in the study area.

\section{REFERENCES}

Abebaw, D and Abelay. K (2001). Factors Influencing adoption of high yielding maize varieties in South Eastern Ethiopia: An application of login Quarterly journal, of international Agriculture 4(2)

Adeola, O.A and Akinwumi, J.A (1993). Maize Production Constraints in Nigeria. A paper presented at the launching of the Maize Association of Nigeria at IITA, Ibadan, Nigeria

Ajala, S.O. (2005). A summary of the final Report Doubling Maize Production in Nigeria in two Years; A Presidential Initiative (Nov2005-Nov2007).

Alamu, J.F (2001). Economic Analysis of Maize Production Using two Technologies in Kaduna State: Journal of Arid Agriculture 11: 125-129

Contryo, (2005) Participatory livestock research: a guide, London, ITDG publishing

Federal Ministry of Agriculture(FMA) (2005). Annual Report, Nigeria.

Feeder, G. Just E.R and D Ziberman (1985). Adoption of Agricultural Innovations in Developing countries. A survey Economic Development cultural change 33.255-298.

Gujarati, D.N.(2004). Basic Econometrics: fourth edition. Tata McGraw-Hill Publishing Company Limited, New Delhi, pp: 580-625.

Karki, L.B (2004). The Impact of Project invention on rural household in Assessment of socio- economic and Environmental implication. A PhD thesis submitted to the University of Giesen, Institute of project and Regional Planning, Giesen, Germany.

Oguntolu, O. W (2005). Factors Affecting Participation of Out growers in Certified Hybrid Maize Seed Production in Giwa Local Government Area. Unpublished M.Sc Thesis, Ahmadu Bello University, Zaria, Nigeria

Onwueme, I.C. (1979) Crop Science. The Camelot Press Limited, Great Britain, 127Pp.

Ouma,J.O.,M.F. Murithi, W. Mwangi, H. Verkuijl, G. Macharia and H.D.Groote (2002). Adoption of maize seed and fertilizer technologies in Embu Distric, Kenya. Mexico,D.F,: CIMMYT. PP:1-21.

Susan, M and Anne, P (1988). Tropical and Sub-tropical food, Macmillan Publisher ltd. 